\title{
Mobil Ortamlarda Kitlesel Açık Çevrimiçi Derslerin (KAÇD) Kullanılabilirliğinin Değerlendirilmesi
}

\author{
Evaluation of Massive Open Online Courses (MOOC) \\ Usability in Mobile Platforms
}

\author{
Esra İŞGÖR ŞIMŞEK**, Bülent Onur TURAN***
}

Öz: $\mathrm{Bu}$ çalışmada, mobil ortamlarda kullanılan Kitlesel Açık Çevrimiçi Derslerin (KAÇD) kullanılabilirliği değerlendirilmiş ve bu ortamlar için kullanılabilirliği arttırmak için önerilerde bulunulmuştur. Çalışmanın kapsamı, yaygın olarak kullanılan KAÇD’leri ele almak ve bu sistemleri cinsiyet, yaş, teknolojik okur-yazarlık ve çevrimiçi ders deneyimi değişkenlerine göre mobil ortamlarda kullanılabilirliğini değerlendirmektir. Araştırma kapsamında CSUQ anketinin Türkçe'ye çevrilmesi ile hazırlanmış ölçek kullanıcılara yöneltilmiştir. Veriler SPSS 20 programı ile işlenmiştir. Elde edilen verilere göre, değerlendirilen sistemler arasında kullanılabilirlik, sistem yararlılığı, bilgi kalitesi ve arayüz kalitesi açısından anlamlı bir fark vardır. Ayrıca sadece yaş değişkeni; kullanılabilirlik, sistem yararlılığı ve bilgi kalitesi değişkenlerinin sistemler arasında farklılık göstermesinde rol oynamaktadır.

Anahtar Kelimeler: Kitlesel açık çevrimiçi ders, kullanılabilirlik, mobil öğrenme

\begin{abstract}
In this study, Massive Open Online Courses (MOOC) used in mobile platforms were evaluated, and attention was drawn to actions that are necessary to improve the usability of these platforms. The scope of this study is to handle the widely used systems, and to evaluate usability of these systems according to gender, age, technological literacy and online course background variables. In this study, a survey which was prepared by translating CSUQ into Turkish was addressed to users. The survey data was processed with SPSS 20 program. According to the findings, there was a significant difference among systems in terms of system usability, system usefulness, information quality and interface quality. Moreover, only age variable has a significant effect in the differences among systems in terms of system usability, system usefulness and information quality.
\end{abstract}

Keywords: Massive open online course, usability, mobile learning

\section{Giriş}

Günümüzde kullandığımız bilgi, elektronik ortamlarda sürekli yer değiştirerek yoculuğuna devam etmiştir (Gülbahar, 2012). Dünden bugüne sürekli bir tartışma konusu olan eğitim de, bilgisayarların günlük yaşamda yer alması ile farklı bir boyut kazanmıştır. Bilgisayarlar sayesinde geleneksel eğitimden elektronik öğrenmeye (e-öğrenme) geçiş yapılması ile eğitimde fırsat eşitliği sağlanmış, zaman ve mekâna bağımlı olmadan bireylere öğrenme firsatı sunulmuştur. Gelişen teknoloji mobil alanda da önemli gelişmelerin kaydedilmesini sağlamıştır. $\mathrm{Bu}$ gelişmeler akıllı telefon, cep bilgisayarı, tablet gibi mobil cihazların giderek yaygınlaşmasını sağlamış ve zamanla e-öğrenme bu gibi mobil cihazlar üzerinden yapılmaya başlanmıştır. Mobil platformlar üzerinden gerçekleşen bu öğrenme biçimi, mobil öğrenme (m-öğrenme) kavramının ortaya çıkmasını sağlamıştır. Gülbahar (2012) m-öğrenmeyi eğitim ve öğretimin PDA denilen dijital kişisel asistanlar, akıllı telefonlar, taşınabilir medya oynatıcılar ve mobil telefonlar gibi mobil araçlar üzerinden karşılanması olarak tanımlanmıştır.

\footnotetext{
*Bu makale, ilk yazarın Mimar Sinan Güzel Sanatlar Üniversitesi Fen Bilimleri Enstitüsü’nde tamamladı̆̆ı yüksek lisans tezinden üretilmiştir.

**Yalova Üniversitesi, Uzaktan Eğitim Uygulama ve Araştırma Merkezi, Yalova,-Türkiye, e-posta: esra.isgor@gmail.com

***Yrd.Doç.Dr., Mimar Sinan Güzel Sanatlar Üniversitesi, Enformatik Bölümü, İstanbul-Türkiye, e-posta: boturan@gmail.com
} 
Geleneksel öğrenme yaklaşımından farklı olan m-öğrenme modelinde öğrenme öğrenci merkezlidir. Öğrenciler dünyanın herhangi bir yerindeki ders kaynaklarına istedikleri mekân ve zamanda erişebilmekte ve dersleri kendi öğrenme hızlarında takip edebilmektedirler (Oran ve Karadeniz, 2007). Hem geleneksel öğrenmeyi desteklemek, hem de uzaktan eğitim vermek amacıyla kullanılan m-öğrenme yaklaşımında, son yıllarda Kitlesel Açık Çevrimiçi Ders (KAÇD) denilen yeni bir öğrenme modeli kullanılmaya başlamıştır. KAÇD, dünyadaki herhangi bir kurumun kendi ders içeriklerini kitleler halindeki gruplara çevrimiçi olarak sunan bir eğitim modelidir. Son yıllarda hızla yaygınlaşan bu eğitim modeli, günümüzde mobil platformlar üzerinden de kullanıcıya sunulmaya başlanmıştır. Ancak web ortamından mobil ortama aktarılan bu sistemlerin bazılarında kullanılabilirlik adına eksikler ön plana çıkmıştır.

\section{M-Öğrenme Ortamları, Kullanılabilirlik ve KAÇD'ler}

Teknolojinin getirdiği yeniliklerle beraber eğitim de evrim geçirmiş, zaman içinde gelişen farklı teknolojilerle eğitim kaynaklarının zaman ve mekân kısıtı olmaksızın kolayca erişilebilir hale gelmesiyle uzaktan eğitimin temelleri atılmıştır (Efiloğlu Kurt, 2015). Uzaktan eğitim "Farklı ortamlarda bulunan öğrenci ve öğretmenlerin, öğrenme-öğretme faaliyetlerini, iletişim teknolojilerini ve posta hizmetleri ile gerçekleştirdikleri bir eğitim sistemi modelini ifade eder" (İşman, 1998, s. 18). Bu modele, bilgisayar destekli sistemlerin ve internetin dâhil edilmesiyle, elektronik öğrenme (e-öğrenme) kavramı ortaya çıkmış ve bu kavram kullanılmaya başlanmıştır. E-öğrenme, bilgi ve iletişim teknolojileri yardımı ve internet/intranet gibi yerel ve geniş alan ağları aracılığı ile zaman ve mekândan bağımsız olarak bilgiye erişimi ve çoklu ortam uygulamaları ile etkileşim sağlanarak, öğretim etkinliklerinin elektronik öğrenme ortamlarında yürütülmesidir (Gülbahar, 2012). Son yıllarda mobil ve iletişim teknolojilerinin hızla gelişmesi, mobil cihazların kullanımını giderek yaygınlaştırmıştır. Günlük hayatta birçok amaç için kullanılan bu cihazlar öğrenme faaliyetlerinde de önemli bir rol oynamaktadır. Bu cihazların öğrenme faaliyetlerinde kullanılmasıyla da e-öğrenme, mobil öğrenmeye doğru taşınmaktadır (Sharples, 2000). Mobil öğrenme, bilgiye herhangi bir mekânda ve zamanda mobil araçlar sayesinde erişilmesini sağlayan bir öğrenme biçimi olarak tanımlanır (Roger, 2011). Steven ve Kitchenham (2011) m-öğrenmeyi, e-öğrenmenin bir alt kümesi gibi düşünmektedirler. Jones ve Jo (2004) ise m-öğrenmenin mobil cihazlar ile e-öğrenmenin kesişimi olduğunu savunmaktadır.

Mobil öğrenme biçiminde kullanıcı, mobil cihazlar ile sürekli etkileşim halindedir. Kullanıcı ile teknolojik arayüzlerin etkileşimlerini inceleyen çalışma alanı İnsan-Bilgisayar Etkileşimi (İBE) olarak isimlendirilmektedir (Olson ve Olson, 2003) ve bu alanın üzerinde en fazla çalıştı̆g konular arasında "Kullanılabilirlik" kavramı bulunmaktadır. Kullanılabilirlik, bir sistemin kullanımıyla belirlenen amaçlara ne derece ulaşıldığının (etkililik), belirlenen amaçların elde edilmesi için harcanması gereken zaman, para, zihinsel çaba vb. kaynakların (etkinlik) ve kullanıcının, sistemi kabul edilebilir bulma derecesinin (tatmin) bir ölçüsüdür (Bevan, 1995). Diğer bir tanıma göre de, kullanıcının bir ürün veya sistemle olan etkileşimini etkileyen faktörlerin bir kombinasyonudur (Nielsen, 1993). Kullanılabilirliğin temel amac1, ürünleri hitap edilen kullanıcıların özellikleri, ihtiyaç ve beklentilerine uygun bir şekilde tasarlamaktır. Üretilen ürünlerin kullanıcıların bilişsel yapısı ve genel kullanım tutumları ile uyumlu olması hedeflenmektedir. Ayrıca ortaya çıkan ürünün etkililiğini, verimliliğini ve memnuniyet derecesini arttırmak da diğer bir kullanılabilirlik amacı olarak belirtilebilir (Gürses, 2005). Kullanılabilirlik daha insanca sistemler oluşturulmasını sağladığı için insan yaşamında çok önemli bir role sahiptir (Çağıltay, 2011). Kullanılabilirlik, kullanıcı memnuniyetinin artmasını, ürüne ve organizasyona yönelik olumlu algıların oluşmasını; ürün geliştirilmesi sırasında harcamaların azaltılmasını; daha eksiksiz bir ürün geliştirilmesini; ürüne yönelik olumsuz durumların oluşma riskinin azaltılmasını; uygulamada oluşabilecek değişikliklerin ve problemlerin sayısının azaltılmasını sağlar (Çağıltay, 2011).

E-öğrenme ve mobil öğrenme dışında, son y1llarda eğitim sistemlerinin en hızlı büyüyen segmentlerinden biri çevrimiçi öğrenmedir. Çevrimiçi öğrenmede son yeniliklerin başında KAÇD olarak adlandırılan Kitlesel Açık Çevrimiçi Dersler gelmektedir (Siemens, 2013). KAÇD, dersin en az bir profesörün katılımı ile kitleler halindeki öğrencilere çevrimiçi 
olarak sunulmasıdır (Voss, 2013). Diğer bir tanıma göre de KAÇD; video dersleri, tartışma forumları, akran değerlendirme gibi çevrimiçi araçlardan oluşan; Stanford, MIT, Edinburgh gibi saygın üniversitelerin derslerini seçmeye olanak veren sistemlerdir (Harding, 2012). KAÇD terimi, ilk olarak 2008 yılında David Cormier ve Bryan Alexandar isimli iki farklı girişimci tarafindan ortaya atılmıştır. Stephen Downes ve George Siemens ise ilk KAÇD'i 2008 yılında çevrimiçi servis ve bir araç olarak ücretsiz bir şekilde oluşturmuşlardır (Downes, 2013). Kanada'da Manitoba Üniversitesi'nde açılan “Connectivism and Connected Knowledge” dersi ilk KAÇD örneğidir. Bu ders, bağlantısallık ilkelerine dayalı, başlangıç ve bitiş zamanı olan, açık erişimli ve ölçeklenebilir bir ders olduğu için çevrimiçi olarak sunulan diğer uzaktan eğitim derslerinden farklı olmuştur. Kredili olarak 24 öğrenciye açılan bu ders, daha sonra açık çevrimiçi kurs şeklinde dönüştürülünce 2200 öğrenci daha ücretsiz bir şekilde derse katılmıştır (Siemens, 2013). İlk KAÇD dersinin bu yoğunlukta ilgi görmesi, 2011 yılında Standford Üniversitesi'nden Sebastian Thrun ve Peter Norvig'in “Artificial Intelligent" dersini ücretsiz ve açı olarak kullanıcılara sunmalarına neden olmuştur. Bu derse 190 ülkeden 160.000 öğrenci kayı1t yaptırmıştır (Pappano, 2012; Waldrop, 2013). Sadece akademik çevrenin değil, aynı zamanda dünyanın birçok yerinden bu kadar yüksek bir sayıda katılımcının ilgisini çektiği için bu ders gerçek anlamda "Kitlesel" Açık Çevrimiçi Ders olarak nitelendirilmektedir (Mehaffy, 2012). Bu ders, içerikleri ve ödevleri içeren özelleştirilebilir bir web sayfasından oluşmaktadır ve bu sayfa bir eğitim yönetim sistemi üzerine kuruludur. Thrun daha sonra Standford Üniversitesi'nden ayrılarak günümüzde en çok bilinen KAÇD'lerden biri olan Udacity'i kazanç elde etmek için kurmuştur (De Freitas, 2013). New York Times tarafindan "KAÇD'lerin Yılı" olarak ilan edilen 2012 yılı içinde (Pappano, 2012) benzer bir şekilde gelir elde etmek için Standford Üniversitesi profesörlerinden Daphne Koller ve Andrew Ng tarafindan Coursera kurulmuştur. Çok geçmeden MIT ve Harvard (De Freitas, 2013) kâr amacı gütmeyen EdX'i 2013 y1lında kurmuştur (Gore, 2014).

Geçtiğimiz 2 y1lda kamuoyunca iyi bilinen Coursera, EdX, Udacity gibi KAÇD’ler elit üniversiteler tarafindan ücretsiz içerik sunması ve medya tarafindan dikkat çekmesi nedeniyle çok yaygın hale gelmiştir (Daniel, 2012). Şekil 1'de görüldügü gibi KAÇD'ler zaman içerisinde giderek artan bir grafiğe sahiptir. Özellikle son iki yıldaki artışın çok ciddi bir oranda olduğu gözlenmektedir.

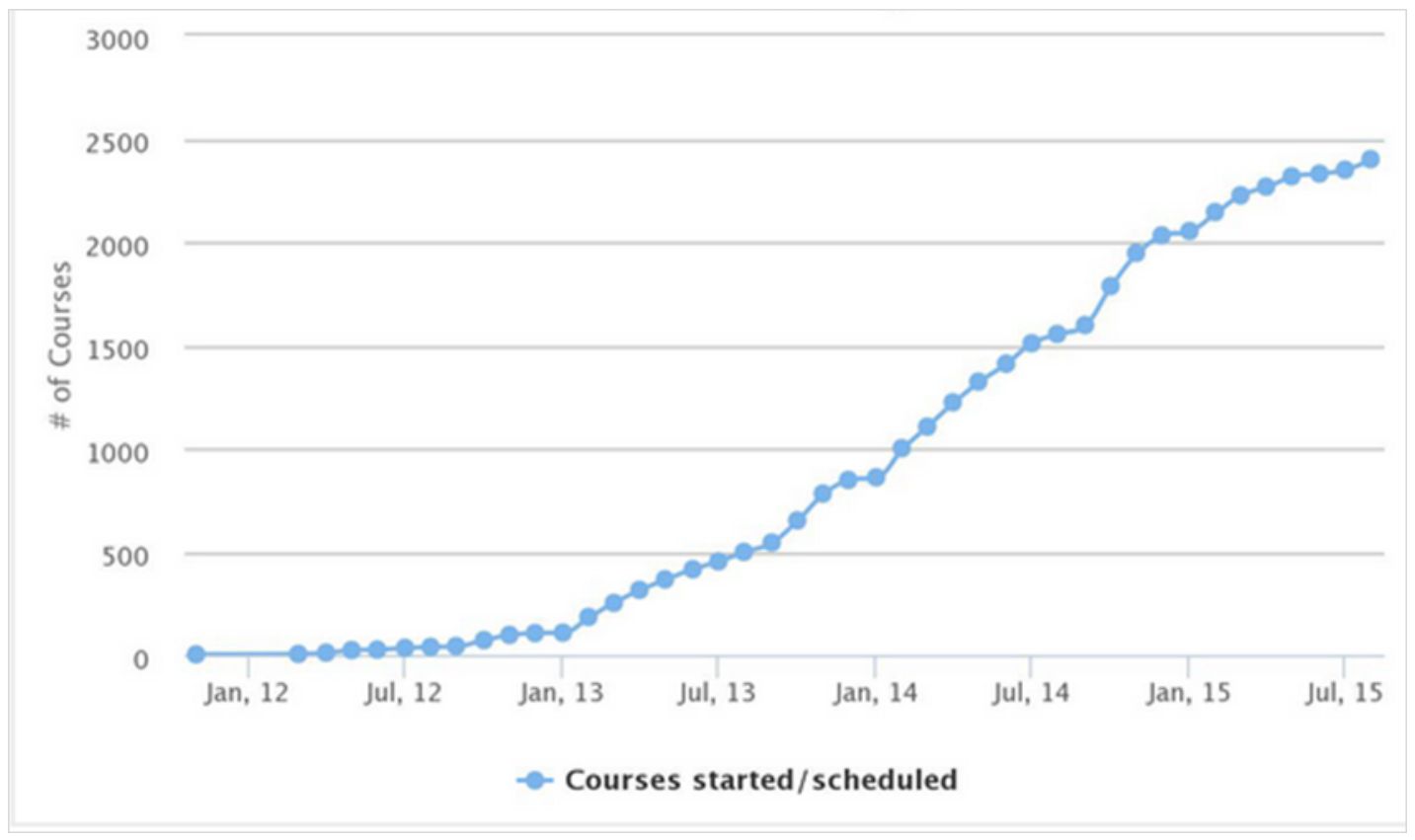

Şekil 1. KAÇD’lerin Zaman İçerisinde Giderek Artan Grafiği (Shah, 2014) 
Günümüzde hızlı bir ivmeye sahip olan KAÇD'lerin geleceğini eğitimciler farklı şekillerde yorumlamışlardır. Ferenstein (2013) bu sistemlerin birçok okul, kolej ve üniversitenin yerini alacağını savunmuştur. Diğer yandan Baggaley (2011) çevrimiçi eğitimin kalite ve pedagojik açıdan zayıf olduğunu savunmakta, Jakson (2013) ise bu derslerin oluşturulmasının zahmetli ve pahalı bir iş olduğunu belirtmektedir. Crispin (2012) de bu tür sistemlerin klasik eğitim ve öğretimi etkilemeyeceğini, bunların birer "Eğitim Teknolojisi Balonu" olduğunu ve bir müddet sonra söneceğini savunmuştur.

Sonuç olarak KAÇD'ler nispeten yeni ve gelişmekte olan ortamlar olduğu için ilerisini tahmin etmek güçtür. Bununla beraber KAÇD'lerin hayat boyu öğrenme için önemli bir kaynak olduğu yadsınamaz ve bu sistemler eğitimde firsat eşitliğini sağlamaktadır.

\section{Araştırmanın Amacı}

$\mathrm{Bu}$ çalışmanın ana amacı mobil ortamlarda kullanılan KAÇD'lerin, ilgili kullanıcı algı ve görüşlerini inceleyerek kullanılabilirliğini değerlendirmektir. Bu bağlamda üç mobil KAÇD sistemi seçilmiş ve karşılaştırmalı analizi yapılmıştır. Kullanıcıların cinsiyet, yaş, teknolojik okur-yazarlık ve daha önce çevrimiçi ders deneyimi değişkenlerinden mobil kullanılabilirliğe etki eden faktörler tespit edilmiş; bu sistemlerin mobil platformlarda kullanılabilirlik açısından eksik yönlerinin belirlenmiş ve iyileştirilmesi için önerilerde bulunulmuştur. Çalışmanın bir amacı da, KAÇD'lerin henüz yeni olması ve alanda yeterli çalışma olmaması nedeniyle yapılacak diğer çalışmalara yol gösterici olmasıdır.

\section{Araştırmanın Problemi}

Alanda yapılan araştırmalar sonucunda mobil ortamlarda KAÇD'lerin kullanılabilirliğine dair kapsamlı bir çalışma bulunmadığı görülmektedir. Bu nedenle bu çalışma kapsamında,

- KAÇD'lerin mobil platformları ile eğitim alan kullanıcıların, sistemlerin kullanılabilirlikleri, yararlılıkları, bilgi kaliteleri ve arayüz kaliteleri hakkındaki algıları nelerdir?

- $\mathrm{Bu}$ algılar cinsiyet, yaş, teknolojik okur-yazarlık ve çevrimiçi ders deneyimi konularında farklılık göstermekte midir? Bu sorulara cevap aranmıştır.

\section{Yöntem}

KAÇD'lerin mobil ortamlarında eğitim alan kullanıcıların, bu sistemlerin kullanılabilirlikleri, yararlı1ıkları, bilgi kaliteleri ve arayüz kaliteleri hakkındaki algılarını ve bu algıların cinsiyet, yaş, teknolojik okur-yazarlık ve çevrimiçi ders deneyimlerine göre farklılık gösterip göstermediğini araştıran bu çalışma nicel araştırma yönteminin kullanıldığı bir çalışmadır.

Araştırma kapsamında, Coursera, Udacity ve Udemy KAÇD'leri örnek olarak seçilmiştir. Belirtilen ortamların örnek olarak seçilmelerinin nedeni, günümüzde yaygın olarak kullanılmaları ve mobil uygulamalarının bulunmasıdır. Bu KAÇD sistemleri ile ilgili kullanıcılara kullanılabilirlik anketi uygulanmış ve kullanıcı görüşleri değerlendirilmiştir. Araştırmada elde edilen veriler, belirtilen amaç ve araştırma sorularına yönelik deneysel bir araştırma modeli çerçevesinde, anket yöntemi ile elde edilmiştir.

Kullanıcıların görüşlerinin yer aldığ 1 anket verileri, SPSS 20 programı ile işlenerek değerlendirilmiştir. $\mathrm{Bu}$ değerlendirmede Mauchly varyans analizi, tekrarlı uygulamaların karşılaştırılmasında tekrarlı ölçümlerde varyans analizi, farklılığın hangi ölçümden kaynaklandığının tespit edilmesinde Bonferroni düzeltme analizi kullanılmıştır. Araştırmada elde edilen verilerin anlamlılık düzeyleri $\mathrm{p}<0,05$ olarak değerlendirilmiştir.

\section{Çalışma Grubu}

KAÇD'lerin Mobil Ortamlarda Kullanılabilirliği anketine 34 erkek, 22 kadın olmak üzere toplam 56 kullanıcı katılmıştır. Tablo 1'de görüldügü gibi bu katılımcıların \% 60,7'sini erkekler, \% 39,3'ünü kadınlar oluşturmaktadır. 
Tablo 1

Cinsiyet

\begin{tabular}{lcc}
\hline Cinsiyet & Kullanıcı Sayıs1 & Yüzde (\%) \\
\hline Erkek & 34 & 60,7 \\
Kadın & 22 & 39,3 \\
Toplam & 56 & 100 \\
\hline
\end{tabular}

Ankete özel, kamu, akademik ve diğer sektörlerden kullanıcılar katılmıştır. Tablo 2'de görüldügü gibi bu katılımcılardan 22 kişi akademik sektörden, 14 kişi kamudan, 11 kişi özel sektörden, 9 kişi de diğer sektörlerdendir. Akademik sektörden katılanlar \% 39,3, kamudan katılanlar \% 25, özel sektörden katılanlar \% 19,6, diğer sektörlerden katılanlar ise \% 16,1'dir.

Tablo 2

Sektör

\begin{tabular}{lcc}
\hline Sektör & Kullanıcı Sayıs1 & Yüzde (\%) \\
\hline Akademik & 22 & 39,3 \\
Kamu & 14 & 25,0 \\
Özel & 11 & 19,6 \\
Diğer & 9 & 16,1 \\
Toplam & 56 & 100 \\
\hline
\end{tabular}

Ankete katılan kullanıcıların eğitim düzeyleri 3 farklı seviyededir. Tablo 3'de görüldügü gibi 29 kişi lisans, 17 kişi yüksek lisans, 10 kişi doktora düzeyindedir. Eğitim düzeyi lisans olan kullanıcılar \% 51,8, yüksek lisans olan kullanıcılar \% 30,4, doktora düzeyi olan kullanıcilar ise \% 17,9'dur.

Tablo 3

Eğitim Düzeyi

\begin{tabular}{lcc}
\hline Eğitim Düzeyi & Kullanıcı Sayısı & Yüzde (\%) \\
\hline Lisans & 29 & 51,8 \\
Yüksek Lisans & 17 & 30,4 \\
Doktora & 10 & 17,9 \\
Toplam & 56 & 100 \\
\hline
\end{tabular}

Ankete katılan kullanıcıların teknolojik okur-yazarlık seviyeleri genel olarak çok iyi ve iyi düzeyindedir. Error! Reference source not found.'de görüldüğü gibi kullanıcılardan 25 kişinin teknolojik okur-yazarlık seviyesi çok iyi, 23 kişinin iyi, 7 kişinin orta, 1 kişinin de çok düşük seviyededir. Yüzdesel olarak teknolojik okur-yazarlık seviyesi çok iyi olanlar \% 44,6, iyi olanlar \% 41,1, orta olanlar \% 12,5, çok düşük olanlar da \% 1,8'dir.

Tablo 4

Teknolojik Okur-Yazarlık Seviyesi

\begin{tabular}{lcc}
\hline Teknolojik & & \\
Okur-Yazarlık Seviyesi & Kullanıcı Sayısı & Yüzde (\%) \\
\hline Cok İyi & 25 & 44,6 \\
İyi & 23 & 41,1 \\
Orta & 7 & 12,5 \\
Çok Düșük & 1 & 1,8 \\
Toplam & 56 & 100 \\
\hline
\end{tabular}

Ankete katılan kullanıcıların günlük internet kullanım süreleri ise Tablo 5'de verilmiştir. Buna göre günlük 1-2 saat internet kullanan kullanıcıların sayısı 3, 2-4 saat kullananlar 13, 4-8 saat kullanan 21, 8 saatten fazla kullananlar ise 19 kişidir. Günlük ortalama 
1-2 saat internet kullanan kişiler \% 5,4, 2-4 saat internet kullanan kişiler \% 23,2, 4-8 saat internet kullanan kişiler \% 37,5, 8 saatten fazla internet kullananlar ise \% 33,9'dur.

Tablo 5

Günlük Ortalama İnternet Kullanım Süresi

\begin{tabular}{lcc}
\hline $\begin{array}{l}\text { Günlük İnternet } \\
\text { Kullanımı }\end{array}$ & Kullanıcı Sayısı & Yüzde (\%) \\
\hline 1-2 Saat & 3 & \\
2-4 Saat & 13 & 5,4 \\
4-8 Saat & 21 & 23,2 \\
8 Saatten Fazla & 19 & 33,5 \\
Toplam & 56 & 100 \\
\hline
\end{tabular}

Ankete katılan kullanıcıların interneti kullanma amaçları da Tablo 6' da verilmiştir. Buna göre bu katılımcılardan 53 kişi eğitim, araştırma ve bilgi edinme amacı ile, 40 kişi bankacılık işlemlerini gerçekleştirme amacı ile, 36 kişi alışveriş yapma amacı ile, 46 kişi sosyalleşme amacı ile, 47 kişi haber, gazete ve dergi okuma amacı ile, 25 kişi oyun ve eğlence amacı ile, 47 kişi de iletişim amacı ile interneti kullanmaktadır. İnterneti eğitim, araştırma ve bilgi edinmek için kullanan kişiler \% 94,6, bankacılık için kullanan \% 71,4, alışveriş için kullananlar \% 64,3, sosyalleşmek için kullananlar \% 82,1, haber, gazete ve dergi okumak için kullananlar \% 83,9, oyun ve eğlenme için kullananlar \% 44,6, iletişim için kullananlar ise \% 83,9 'dur.

Tablo 6

Kullanıcıların İnterneti Kullanma Amaçları

\begin{tabular}{lcc} 
İnterneti Kullanım Amaçları & Kullanıcı Sayısı & Yüzde (\%) \\
\hline Eğitim /Arastırma/Bilgi & 53 & 94,6 \\
Bankac1lı İslemleri & 40 & 71,4 \\
Alısveris & 36 & 64,3 \\
Sosyalleșme (Sosyal Ağlar/ & 46 & 82,1 \\
Haber/Gazete/Dergi & 47 & 83,9 \\
Oyun/Eğlence & 25 & 44,6 \\
İletișim (E-mail) & 47 & 83,9 \\
\hline
\end{tabular}

Ankete katılan kullanıcıların uygulama sırasında kullandıkları telefonların işletim sistemleri ise Tablo 7'de verilmiştir. Buna göre iOS işletim sistemi kullananların sayısı 19, Android işletim sistemi kullananların sayısı ise sayısı ise 37'dir. iOS işletim sisteminin kullanımı \% 33,9, Android işletim sisteminin kullanımı ise \% 66,1'dir.

Tablo 7

Kullanıcıların Kullandıkları Cihazların İşletim Sistemleri

\begin{tabular}{lcc}
\hline İşletim Sistemi & Sayıs1 & Yüzde (\%) \\
\hline iOS & 19 & 33,9 \\
Android & 37 & 66,1 \\
Windows & 0 & 0 \\
Diğer & 0 & 0 \\
Toplam & 56 & 100 \\
\hline
\end{tabular}

Ankete katılan kullanıcıların daha önce çevrimiçi bir eğitim alıp almadıklarının verileri Tablo 8'de verilmiştir. Buna göre bu kullanıcılardan 30 kişi daha önce çevrimiçi bir eğitim almış, 26 kişi ise almamıştır. Çevrimiçi eğitim alanlar \% 53,6, almayanlar ise $\% 46,4$ 'dür. 
Tablo 8

Kullanıcıların Daha Önce Çevrimiçi Eğitim Alma Durumları

\begin{tabular}{lcc}
\hline Daha Önce Çevrimiçi & & \\
Eŭitim Alanlar & Kullanıcı Sayısı & Yüzde (\%) \\
\hline Evet & 30 & 53,6 \\
Hayır & 26 & 46,4 \\
Toplam & 56 & 100 \\
\hline
\end{tabular}

\section{Veri Toplama Araçları}

Bu çalışmada verilerin toplanması için ilk olarak kullanıcıların cinsiyet, yaş, eğitim düzeyi gibi demografik bilgilerin belirlenmesini sağlayan 10 soruluk "Kullanıcı Bilgi Anketi" uygulanmıştır. Daha sonra kullanıcılardan Coursera, Udacity ve Udemy sistemlerinin mobil ortamlardaki uygulamaları, kullanıcının uygulamanın arayüzünü tanıyana kadar incelemeleri istenmiştir. Bu incelemenin ardından kullanıcılara bir dizi görev içeren "Görevler Listesi" verilmiş ve listede bulunan görevleri sıra ile tamamlamaları beklenmiştir. Bu görevler sisteme üye olma, belirli bir dersi aratma, bu dersin belirtilen bir haftasına gitme gibi uygulama içerisinde rahatça gezinebilmeyi ve uygulamayı kolay bir şekilde kullanmayı gerektirecek görevlerdir. Her bir sistem için bu gibi görevleri ayrı ayrı tamamlayan kullanıcılara son olarak yine her sistem için ayrı olarak "KAÇD'lerin Mobil Ortamlarda Kullanılabilirliği Anketi" uygulatılmıştır. $\mathrm{Bu}$ anket, CSUQ (Computer System Usability Questionnaire) anketinin Türkçe'ye çevrilmesi ile oluşturulmuştur. CSUQ anketi, IBM tarafindan geliştirilen, geçerliliği onaylanan ve kullanılabilirlik alanında literatürde yaygın olarak kullanılan bir ankettir. 19 maddeden oluşan bu anketin 8 maddesi sistem yararlılığ 1 , maddesi bilgi kalitesi, 3 maddesi arayüz kalitesi ve tüm maddeler de kullanılabilirlik ile ilgilidir. Her madde, 1 (Kesinlikle katılmıyorum) - 7 (Kesinlikle katılıyorum) şeklinde puanlanmaktadır. Anket maddelerinin Türkçe'ye çevrilmesinde konu alanındaki iki uzmandan destek alınmıştır. Bu maddelerinin kapsam geçerliği yine konu alanındaki iki uzman tarafından incelenmiştir ve ankette gerekli olan düzenlemeler yapıldıktan sonra geçerli bulunmuştur. Anket maddelerinin güvenirliği ise SPSS 20 programında işlenmiş; Cronbach Alpha ve Spearman-Brown güvenirlik katsayıları hesaplanmıştır. Anket üç ayrı sisteme uygulandığı için, güvenirlik katsayıları da her sistem için ayrı ayrı ele alınmıştır. Tablo 9'da görüldüğü üzere bu katsayılar anket sorularının güvenilir olduğunu göstermektedir.

Tablo 9

Anketin KAÇD'ler İçin Geçerlilik Test Sonuçları

\begin{tabular}{lcc}
\hline KAÇD & Cronbach Alpha & Spearman-Brown \\
\hline Coursera & 0,957 & 0,921 \\
Udacity & 0,964 & 0,895 \\
Udemy & 0,976 & 0,961 \\
\hline
\end{tabular}

\section{Bulgular}

$\mathrm{Bu}$ bölümde anket maddelerinden elde edilen demografik bilgiler, kullanılabilirlik, sistem yararlılığı, bilgi kalitesi ve arayüz kalitesi değişkenleriyle ilgili bulgular ve bu bulgularla ilgili yorumlar yer almaktadır. Bu bulguların elde edilmesinde Mauchly varyans analizi, tekrarlı ölçümlerde ANOVA analizi, Bonferroni düzeltme analizi kullanılmıştır. Bu analizler kullanılabilirlik, sistem yararlılığı, bilgi kalitesi ve arayüz kalitesi değişkenleri ile cinsiyet, yaş, teknolojik okur-yazarlık seviyesi ve çevrimiçi ders deneyimi değişkenlerine göre farklılık gösterip göstermediği araştırmaktadır.

\section{KAÇD’lerin Mobil Ortamlarda Kullanılabilirliği İle İlgili Bulgular}

KAÇD'lerin mobil ortamlarda kullanılabilirliğin ölçmek için kullanılan ve 19 maddeden oluşan ankette 1-8 arası maddeler sistem yararlılığını, 9-15. arası maddeler bilgi kalitesini, 16 ve 18 . maddeler arayüz kalitesini ölçmektedir. Ankette bulunan 19 maddenin ortalaması da 
kullanılabilirlik değişkeni olarak değerlendirilmiştir. Buna göre bu dört değişken için ortalama değerler Coursera ve Udemy sistemlerinde birbirine yakın, Udacity'de ise daha düşüktür.

Araştırma sonucunda Coursera, Udacity ve Udemy platformlarının; Kullanılabilirlik skorları arasında istatistiksel olarak anlamlı bir fark olduğu tespit edilmiştir $[\mathrm{F}(1,77,97,20)=$ 26,35, p < ,01]. Tablo 10'da görüldüğü gibi Coursera sisteminin kullanılabilirlik düzeyinin $(\mathrm{x}=5,028, \mathrm{SS}=, 987)$, Udacity sisteminin kullanılabilirlik düzeyinden $(\mathrm{x}=3,863, \mathrm{SS}=1,151)$ anlamlı bir şekilde yüksek olduğu görülmüş̧ür. Udemy sisteminin kullanılabilirlik düzeyinin de $(\mathrm{x}=5,134, \mathrm{SS}=1,259)$, Udacity sisteminin kullanılabilirlik düzeyinden $(\mathrm{x}=3,863, \mathrm{SS}=1,151)$ anlamlı bir şekilde yüksek olduğu görülmüştür. Coursera $(x=5,028, S S=, 987)$ ile Udemy $(\mathrm{x}=5,134, \mathrm{SS}=1,259)$ sistemlerinin kullanılabilirlik düzeyleri arasında ise anlamlı bir fark görülmemiştir. Araştırma sonucunda bu sistemlerin kullanılabilirlik skorlarının farklılaşmasında cinsiyet $[\mathrm{F}(1,72,93,24)=1,81, \mathrm{p}=, 17]$, teknolojik okur-yazarlık seviyesi $[\mathrm{F}(3,53,93,62)=$ $, 33, \mathrm{p}=, 84]$ ve çevrimiçi ders deneyimi $[\mathrm{F}(1,76,94,8)=, 59, \mathrm{p}=, 54]$ değişkenlerinin anlaml etkisi olmadığ istatistiksel olarak saptanmıştır. Yaş $[\mathrm{F}(1,74,93,78)=3,78, \mathrm{p}=, 03]$ değişkeninin ise anlamlı etkisi olduğu tespit edilmiştir.

Tablo 10

Ortamların Kullanılabilirlik Skorları

\begin{tabular}{llll}
\hline & Coursera & Udacity & Udemy \\
\hline $\mathrm{x}$ & 5,028 & 3,863 & 5,134 \\
$\mathrm{SS}$ & 0,987 & 1,151 & 1,259 \\
\hline
\end{tabular}

Sistem yararlılığ skorları arasında istatistiksel olarak anlamlı bir fark olduğu tespit edilmiştir $[\mathrm{F}(2,110)=19,50, \mathrm{p}<, 01]$. Tablo 11 'de görüldügü gibi Coursera sisteminin sistem yararlılığ 1 düzeyinin $(\mathrm{x}=5,134, \mathrm{SS}=, 992)$, Udacity sisteminin sistem yararlıllı̆ $(\mathrm{x}=4,022, \mathrm{SS}=1,304)$ anlamlı bir şekilde yüksek olduğu görülmüştür. Udemy sisteminin sistem yararlı1ığ düzeyinin de $(x=5,167, S S=1,320)$, Udacity sisteminin sistem yararlılı̆̆ 1 düzeyinden $(x=4,022, S S=1,304)$ anlamlı bir şekilde yüksek olduğu görülmüştür. Coursera $(x=5,134$, $\mathrm{SS}=, 992)$ ile Udemy $(\mathrm{x}=5,167, \mathrm{SS}=1,320)$ sistemlerinin sistem yararlılığ düzeyleri arasında ise anlamlı bir fark görülmemiştir. Araştırma sonucunda bu sistemlerin sistem yararlılığı skorlarının farklılaşmasında cinsiyet $[\mathrm{F}(2,108)=1,600, \mathrm{p}=, 21]$, teknolojik okur-yazarlık seviyesi $[\mathrm{F}(4$, $106)=, 142, p=, 97]$ ve çevrimiçi ders deneyimi $[F(2,108)=, 255, p=, 78]$ değiş̧kenlerinin anlamlı etkisi olmadığ 1 istatistiksel olarak saptanmıştır. Yaş $[F(2,108)=3,50, \quad p=, 03]$ değişkeninin ise anlamlı etkisi olduğu tespit edilmiştir.

Tablo 11

Ortamların Sistem Yararlılı̆̆ Skorlar1

\begin{tabular}{llll}
\hline & Coursera & Udacity & Udemy \\
\hline $\mathrm{x}$ & 5,134 & 4,022 & 5,167 \\
$\mathrm{SS}$ & 0,992 & 1,304 & 1,320 \\
\hline
\end{tabular}

Bilgi kalitesi skorları arasında istatistiksel olarak anlamlı bir fark olduğu tespit edilmiştir $[\mathrm{F}(1,74,95,65)=27,40, \mathrm{p}<, 01]$. Tablo 12'de görüldüğü gibi Coursera sisteminin bilgi kalitesi düzeyinin $(\mathrm{x}=5,000, \mathrm{SS}=1,088)$, Udacity sisteminin bilgi kalitesi düzeyinden $(\mathrm{x}=3,832, \mathrm{SS}=1,140)$ anlamlı bir şekilde yüksek olduğu görülmüştür. Udemy sisteminin bilgi kalitesi düzeyinin de $(\mathrm{x}=5,140, \mathrm{SS}=1,314)$, Udacity sisteminin bilgi kalitesi düzeyinden $(\mathrm{x}=3,832, \mathrm{SS}=1,140)$ anlamlı bir şekilde yüksek olduğu görülmüştür. Coursera $(x=5,000$, $\mathrm{SS}=1,088)$ ile Udemy $(\mathrm{x}=5,140, \mathrm{SS}=1,314)$ sistemlerinin bilgi kalitesi düzeyleri arasında ise anlamlı bir fark görülmemiştir. Araştırma sonucunda bu sistemlerin bilgi kaliteleri skorlarının farklılaşmasında cinsiyet $[\mathrm{F}(1,72,93,06)=1,06, \mathrm{p}=, 34]$, teknolojik okur-yazarlık seviyesi $[\mathrm{F}(3,47,92,07)=, 20, \mathrm{p}=, 92]$ ve çevrimiçi ders deneyimi $[\mathrm{F}(1,73,93,30)=, 37, \mathrm{p}=, 66]$ 
değişkenlerinin anlamlı etkisi olmadığı istatistiksel olarak saptanmıştır. Yaş $[F(1,71,92,30)=$ $3,66, \mathrm{p}=, 04]$ değişkeninin ise anlamlı etkisi olduğu tespit edilmiştir.

Tablo 12

Ortamların Bilgi Kalitesi Skorları

\begin{tabular}{llll}
\hline & Coursera & Udacity & Udemy \\
\hline $\mathrm{x}$ & 5,000 & 3,832 & 5,140 \\
$\mathrm{SS}$ & 1,088 & 1,140 & 1,314 \\
\hline
\end{tabular}

Arayüz kalitesi skorları arasında istatistiksel olarak anlamlı bir fark olduğu tespit edilmiştir $[\mathrm{F}(2,110)=18,69, \mathrm{p}<, 01]$. Tablo 13 ' de görüldügü gibi Coursera sisteminin arayüz kalitesi düzeyinin $(\mathrm{x}=4,833, \mathrm{SS}=1,342)$, Udacity sisteminin arayüz kalitesi düzeyinden $(x=3,661, S S=1,403)$ anlamlı bir şekilde yüksek olduğu görülmüştür. Udemy sisteminin arayüz kalitesi düzeyinin de $(\mathrm{x}=4,994, \mathrm{SS}=1,445)$, Udacity sisteminin arayüz kalitesi düzeyinden $(x=3,661, S S=1,403)$ anlamlı bir şekilde yüksek olduğu görülmüştür. Coursera $(x=4,833$, $\mathrm{SS}=1,342)$ ile Udemy $(\mathrm{x}=4,994, \mathrm{SS}=1,445)$ sistemlerinin arayüz kalitesi düzeyleri arasında ise anlamlı bir fark görülmemiştir. Araştırma sonucunda, bu sistemlerin arayüz kaliteleri skorlarının farklılaşmasında, cinsiyet $[\mathrm{F}(1,77,95,36)=2,44, \mathrm{p}=, 10]$, yaş $[\mathrm{F}(1,76,95,15)=2,47, \mathrm{p}=, 10]$, teknolojik okur-yazarlık seviyesi $[\mathrm{F}(4,106)=, 977, \mathrm{p}=, 42]$ ve çevrimiçi ders deneyimi $[\mathrm{F}(1,80$, $97,06)=2,30, \mathrm{p}=, 11]$ değişkenlerinin anlamlı etkisi olmadığ edilmiştir.

Tablo 13

Ortamların Arayüz Kalitesi Skorları

\begin{tabular}{llll}
\hline & Coursera & Udacity & Udemy \\
\hline $\mathrm{x}$ & 4,833 & 3,661 & 4,994 \\
$\mathrm{SS}$ & 1,342 & 1,403 & 1,445 \\
\hline
\end{tabular}

Özet olarak, sistemlerin kullanılabilirlik, sistem yararlılı̆g, bilgi kalitesi ve arayüz kalitesi bakımından farklılıklarının araştırılmasında tekrarlı ölçümlerde varyans analizi testi kullanılmıştır. Bu testin varsayımı olan küresellik koşulu (Sphericty), Mauchly varyans analizi testi ile kontrol edilmiş ve küreselliğin ihlal edildiği durumlarda yani bu testte p değerinin 0,05 'den küçük olması durumunda Greenhouse-Geisser düzeltmesi ile sonuç değerlendirilmiştir. Tablo 14'de görüldüğü gibi analizlerden elde edilen sonuçlara göre değerlendirilen üç sistem arasında kullanılabilirlik, sistem yararlılığı, bilgi kalitesi ve arayüz kalitesi bakımından istatiksel açıdan anlamlı bir fark bulunmuştur. Ayrıca, sadece yaş değişkeninin kullanılabilirlik, sistem yararlılığı ve bilgi kalitesi değişkenlerinin sistemler arasında farklılık göstermesinde rol oynadığı görülmüştür. Cinsiyet, teknolojik okur-yazarlık, çevrimiçi ders deneyimi değişkenlerinin sistemlerin kullanılabilirlik, sistem yararlılığı, bilgi kalitesi ve arayüz kalitesi değerlendirilmesinde anlamlı bir etkiye sahip olmadığı gözlemlenmiştir.

Tablo 14

Kullanılan Analizler

\begin{tabular}{lll}
\hline Değişkenler & Küresellik İhlali & Kullanılan Analiz \\
\hline Kullanılabilirlik & Evet & Greenhouse-G. \\
Cinsiyet & Evet & Greenhouse-G. \\
Yaş & Evet & Greenhouse-G. \\
Teknolojik Okur-Yazarlık & Evet & Greenhouse-G. \\
Çevrimiçi Ders Deneyimi & Evet & Greenhouse-G. \\
\hline Sistem Yararlılığı & Hayır & Sphericity A. \\
Cinsiyet & Hayır & Sphericity A. \\
Yaş & Hayır & Sphericity A.
\end{tabular}




\begin{tabular}{cll}
$\begin{array}{c}\text { Teknolojik Okur-Yazarlık } \\
\text { Çevrimiçi Ders Deneyimi }\end{array}$ & Hayır & Sphericity A. \\
Hayır & Evet & Greenhouse-G. \\
\hline Bilgi Kalitesi & Evet & Greenhouse-G. \\
Cinsiyet & Evet & Greenhouse-G. \\
Yaş & Evet & Greenhouse-G. \\
Teknolojik Okur-Yazarlık & Greenhouse-G. \\
Çevrimiçi Ders Deneyimi & Evet & Sphericity A. \\
\hline Arayüz Kalitesi & Hayır & Greenhouse-G. \\
Cinsiyet & Evet & Greenhouse-G. \\
Yaş & Evet & Sphericity A. \\
Teknolojik Okur-Yazarlık & Hayır & Greenhouse-G. \\
Çevrimiçi Ders Deneyimi & Evet &
\end{tabular}

\section{Sonuç ve Değerlendirme}

Gelişen teknoloji ile mobil alanda önemli gelişmelerin kaydedilmesi, günümüzde eğitim ve öğretim süreçlerinde mobil araçların kullanımını arttırmaktadır. Zaman, mekân ve öğrenme türü gibi sınırlılıkları ortadan kaldıran bu araçlar, öğrenene esnek bir öğrenme ortamı sunmakta ve bu durum mobil öğrenmenin daha da yaygınlaşmasını sağlamaktadır. Bu araçları, öğrenim sürecinde daha etkili kılmak için dikkat edilmesi gereken belli başlı konulardan biri de bu araçların kullanılabilirliğidir. $\mathrm{Bu}$ çalışma, mobil ortamlar için geliştirilen KAÇD'lerde kullanılabilirlik adına dikkat edilmesi gereken noktalara odaklanmıştır. Seçilen üç KAÇD'de (Coursera, Udacity ve Udemy) katılımcilara sunulmuş, bu sistemleri mobil ortamlarda incelemeleri ve ardından kendilerine verilen görevleri tamamlamaları istenmiştir. Daha sonra bu sistemleri değerlendirmeleri için kullanıcılara anket uygulanmıştır. Anket sayesinde bu sistemlerde kullanılabilirliğe ne kadar dikkat edildiği değerlendirilmiş ve bu bağlamda kullanıcı görüşleri ele alınmıştır. Kullanıcıların görüşlerinin yer aldığı anket verileri SPSS 20 programı ile işlenmiştir. Değerlendirilen sistemler kullanılabilirlik, sistem yararlılı̆̆ı, bilgi kalitesi ve arayüz kalitesi bakımından birbirleriyle karşılaştırılmıştır. Ayrıca bu değişkenler ile kullanıcıların demografik özellikleri (cinsiyet, yaş, teknolojik okur-yazarlık ve çevrimiçi ders deneyimi) arasındaki ilişkileri incelenmiştir. $\mathrm{Bu}$ sistemlerin karşılaştırılmaları sonucunda sistemler arasında elde edilen farklar şu şekilde açıklanmaktadır:

- Kullanılabilirlik açısından üç sistem arasında anlamlı bir fark bulunduğu tespit edilmiştir. Buna göre, Coursera sisteminin kullanılabilirlik düzeyinin, Udacity sisteminin kullanılabilirlik düzeyinden anlamlı bir şekilde yüksek olduğu görülmüştür. Aynı şekilde Udemy sisteminin kullanılabilirlik düzeyinin de, Udacity sisteminin kullanılabilirlik düzeyinden anlamlı bir şekilde yüksek olduğu tespit edilmiştir. Ancak Coursera ile Udemy sistemlerinin kullanılabilirlik düzeyleri arasında anlamlı bir fark görülmemiştir. Sistemlerin kullanılabilirlik düzeyinin farklılaşmasında kullanıcıların cinsiyet, teknolojik okur-yazarlık ve çevrimiçi ders deneyimi değişkenlerinin anlamlı bir rol oynamadığı görülmüştür. Ancak yaş değişkeninin kullanılabilirlik düzeyinin farklılaşmasında anlamlı bir rol oynadığı tespit edilmiştir. Verilerden elde edilen sonuçlara göre, Coursera sisteminin kullanılabilirlik düzeyini, genç ve orta yaş grubundaki kullanıcılar birbirine yakın bulmuşlardır. Udacity'de orta yaş grubundakiler sistemi gençlere göre daha kullanılabilir bulmuş iken, Udemy'de genç grubundaki kullanıcılar sistemi orta yaş grubuna göre daha kullanılabilir bulmuşlardır.

- Sistem yararlılığı açısından da üç sistem arasında anlamlı bir fark bulunduğu tespit edilmiştir. Buna göre, Coursera sisteminin sistem yararlılı̆̆ düzeyinin, Udacity sisteminin sistem yararlılığı düzeyinden anlamlı bir şekilde yüksek olduğu görülmüştür. Aynı şekilde Udemy sisteminin sistem yararlılı̆̆ 1 düzeyinin de, Udacity sisteminin sistem yararlılığı düzeyinden anlamlı bir şekilde yüksek olduğu tespit edilmiştir. Ancak Coursera ile Udemy sistemlerinin sistem yararlılığı düzeyleri arasında anlamlı bir fark görülmemiştir. Sistem yararlılığı düzeyinin farklılaşmasında kullanıcıların cinsiyet, 
teknolojik okur-yazarlık ve çevrimiçi ders deneyimi değişkenlerinin anlamlı bir rol oynamadığı görülmüştür. Ancak yaş değişkeninin kullanılabilirlik düzeyinin farklılaşmasında anlamlı bir rol oynadığ sonuçlara göre, Coursera sisteminin sistem yararlılığı düzeyini, genç ve orta yaş grubundaki kullanıcılar birbirine yakın bulmuşlardır. Udacity'de orta yaş grubundakiler sistemi gençlere göre daha yararlı bulmuş iken, Udemy’de genç grubundaki kullanıcılar sistemi orta yaş grubuna göre daha yararlı bulmuşlardır.

- Bilgi kalitesi açısından üç sistem arasında anlamlı bir fark bulunduğu tespit edilmiştir. Buna göre, Coursera sisteminin bilgi kalitesi düzeyinin, Udacity sisteminin bilgi kalitesi düzeyinden anlamlı bir şekilde yüksek olduğu görülmüştür. Aynı şekilde Udemy sisteminin bilgi kalitesi düzeyinin de, Udacity sisteminin bilgi kalitesi düzeyinden anlamlı bir şekilde yüksek olduğu tespit edilmiştir. Ancak Coursera ile Udemy sistemlerinin bilgi kalitesi düzeyleri arasında anlamlı bir fark görülmemiştir. Sistemlerin bilgi kalitesi düzeyinin farklılaşmasında kullanıcıların cinsiyet, teknolojik okur-yazarlık ve çevrimiçi ders deneyimi değişkenlerinin anlamlı bir rol oynamadığı görülmüştür. Ancak yaş değişkeninin bilgi kalitesi düzeyinin farklılaşmasında anlamlı bir rol oynadığı tespit edilmiştir. Verilerden elde edilen sonuçlara göre, Coursera sisteminin bilgi kalitesi düzeyini, genç ve orta yaş grubundaki kullanıcılar birbirine yakın bulmuşlardır. Udacity'de orta yaş grubundakiler sistemi gençlere göre bilgi kalitesi yönünden daha iyi bulmuş iken, Udemy'de genç grubundaki kullanıcılar sistemi orta yaş grubuna göre daha iyi bulmuşlardır.

- Arayüz kalitesi açısından üç sistem arasında anlamlı bir fark bulunduğu tespit edilmiştir. Buna göre, Coursera sisteminin arayüz kalite düzeyinin, Udacity sisteminin arayüz kalite düzeyinden anlamlı bir şekilde yüksek olduğu görülmüştür. Udemy sisteminin arayüz kalite düzeyinin de, Udacity sisteminin arayüz kalite düzeyinden anlamlı bir şekilde yüksek olduğu görülmüştür. Coursera ile Udemy sistemlerinin arayüz kalite düzeyleri arasında ise anlamlı bir fark görülmemiştir. Sistemlerin arayüz kalite düzeyinin farklılaşmasında kullanıcıların cinsiyet, yaş, teknolojik okur-yazarlık ve çevrimiçi ders deneyimi değişkenlerinin anlamlı bir rol oynamadığı görülmüştür.

$\mathrm{Bu}$ sonuçlara dayanarak mobil ortam için yeni bir KAÇD tasarlanacağı zaman dikkat edilmesi gereken noktalar için şu önerilerde bulunulabilir:

- Sistem filtrelemeye uygun olmali; her yerden ve her zaman erişime imkân vermeli; kullanım kolaylığı sunmalı; öğrenenle öğretici arasında iletişime izin vermeli; hata mesajları ve yardım gibi konularda kullanıcıyı yeteri kadar bilgilendirmelidir.

- Sistem arayüzü çoklu dil desteğine uygun olmalı; arayüzünde bulunan simgeler amacına yönelik alanları belirtmeli; kullanılan kelime ve kavramlar kullanıcıya tanıdık olmalı ve kendi içinde tutarlı olmalıdır.

- Sistemdeki derslerde altyazı seçeneği olmalı; dersler ön bilgi içermeli; kullanılan dil basit, sade, açık ve yeterli olmalıdır.

- Sistem hem deneyimli kullanıciya hem de deneyimsiz kullanıciya hitap etmeli; kullanıcıların internete erişimlerinin olmadığı zamanlarda da içeriklere ulaşabilmeleri için ders içeriklerinin indirilmesine imkân vermelidir. Kullanıcılar dil, ders kategorisi, içerik gibi öğeleri filtreleyebilmeli; üyelik gibi işlemleride mobil cihazlar üzerinden yapabilmelidir.

Özet olarak bu çalışmada, KAÇD'lerin mobil ortamlardaki kullanılabilirliği değerlendirilmiş; seçilen üç tane mobil sistem karşılaştırılmış; kullanıcıların cinsiyet, yaş, teknolojik okur-yazarlık ve çevrimiçi ders deneyimi değişkenlerinden mobil kullanılabilirliğe etki edenler tespit edilmiş; bu sistemlerin, mobil platformlarda kullanılabilirlik açısından eksik yönleri belirlenmiş ve iyileştirilmesi adına yapılması gerekenler araştırılarak önerilerde bulunulmuştur. $\mathrm{Bu}$ çalışmada sunulan öneriler ile bir mobil KAÇD tasarlanacağı zaman göz 
önünde bulundurulması gereken etmenlere dikkat çekilmiş; yapılan araştırmanın alanda yapılacak diğer çalışmalara kaynak olması hedeflemiştir.

\section{Kaynaklar}

Baggaley, J. (2011). Harmonising global education: from Genghis Khan to Facebook. London and New York: Routledge.

Bevan, N. (1995, July). Human-computer interaction standards. Proceedings of the 6th International Conference on Human-Computer Interaction. Yokohama, Japan, Elsevier, 885-890.

Crispin, W. (2012). MOOCs and other ed-tech bubbles. Erişim adresi: http://edtechnow.net/2012/12/29/moocs-and-other-ed-tech-bubbles

Çağıltay, K. (2011). Insan bilgisayar etkileşimi ve kullanılabilirlik mühendisliği: teoriden pratiğe. Ankara: ODTÜ Yayınc1lı.

Daniel, J. (2012). Making sense of moocs: musings in a maze of myth, paradox and possibility. Journal of Interactive Media in Education, 18.

De Freitas, S. (2013) MOOCs: The final frontier for higher education. Erişim adresi: http://benhur.teluq.uquebec.ca/ted/Ressources/mooc.pdf

Downes, S. (2013) Quality of massive open online courses by Stephen Downes. Erişim adresi: http://mooc.efquel.org/week-2-the-quality-of-massive-open-online-courses-by-stephendownes/\#sthash.YOitClcH.dpuf

Efiloğlu Kurt, Ö. (2015). Üniversite öğrencilerinin uzaktan eğitime bakış açılarının teknoloji kabul modeli ve bilgi sistemleri başarı modeli entegrasyonu ile belirlenmesi. Uluslararası Alanya Işsletme Fakültesi Dergisi, 7(3), 223-234.

Ferenstein, G. (2013) Online education is replacing physical colleges at a crazy fast pace. Erişim adresi: http://techcrunch.com/2013/02/11/a-huge-month-online-education-isreplacing-physical-colleges-at-a-crazy-fast-pace/

Gore, H. (2014). Massive open online courses (MOOCs) and their impact on academic library services: exploring the issues and challenges. New Review of Academic Librarianship, 20(1), 4-28.

Gülbahar, Y. (2012). E-Öğrenme. Ankara: Pegem Akademi.

Gürses, E. (2005). Web sitelerinde kullanılabilirlik çalışmaları ve kullanılabilirlik değerlendirme yöntemleri. Akademik Bilişim 2005, Adana.

Harding, N. (2012) The massive oppen-online-course online course revolution hits the UK. Erişim adresi: http://thepositive.com/mooc-massive-oes-uk/

İşman, A. (1998). Uzaktan eğitim. Adapazarı: Değişim Yayınları.

Jakson, N. M. (2013). What shapes the future?. Business Officer, 38-45.

Jones, V. ve Jo, H. J. (2004). Ubiquitous learning environment: an adaptive teaching system using ubiquitous technology. Proceedings of the 21st ASCILITE Conference. Perth, Western Australia, 468-474.

Laxmi, V. ve Gure, G. S. (2015). Massive open online courses: new imperative in education. International Journal of Research in Engineering, IT \& Social Sciences, 5(3).

Mehaffy, G. L. (2012). Challenge and change. Educause Review, 47, 25-41.

Nielsen, J. (1993). Usability engineering. London: Academic Press.

Olson, G.M. ve Olson, J. S. (2003). Human-computer interaction: psychological aspects of the human use of computing. Annual Review of Psychology, 54, 491-516.

Oran, M. K. veKaradeniz, Ş. (2007). İnternet tabanlı uzaktan eğitimde mobil öğrenmenin rolü. Akademik Bilişim 2007, 31 Ocak-2 Şubat 2007, Dumlupınar Üniversitesi, Kütahya.

Pappano, L. (2012) The year of the MOOC. The New York Times. Erişim adresi: http://www.nytimes.com/2012/11/04/education/edlife/massive-open-online-courses-aremultiplying-at-a-rapid-pace.html?pagewanted=1\&_r $=0$

Roger, K. D. (2011). Mobile learning devices. Bloomington: Solution Tree Press. 
Shah, D. (2014) Online courses raise their game: a review of MOOC stats and trends in 2014. Erişim adresi: https://www.edsurge.com/n/2014-12-26-moocs-in-2014-breaking-downthe-numbers

Sharples, M. (2000). The design of personal mobile technologies for lifelong learning. Computers and Education, 34, 177-193.

Siemens, G. (2013). Massive open online courses: innovation in education. R. McGreal, W. Kinuthia ve S.Marshall (Yay. haz.). Open Educational Resources: Innovation, Research and Practice içinde (ss.5-16). Canada: Commonwealth of Learning, Athabasca University.

Steven, D. ve Kitchenham, A. (2011). An analysis of mobile learning in education, business, and medicine. A. Kitchenham (Yay. haz.), Models for Interdisciplinary Mobile Learning:Delivering Information to Students içinde (ss.1-25). IGI Publication.

Voss, B. D. (2013). Massive open online courses (MOOCs): A primer for university and college board members. An AGB White Paper. Association of Governing Boards, Washington, D.C.

Waldrop, M. M. (2013, March). Online learning: campus 2.0: Massive open online courses are transforming higher education - and providing fodder for scientific research. Nature Magazine, 495, 160-163.

\section{Extended Abstract \\ Introduction}

Online learning is one of the fastest growing segments in educational world. One of the latest innovations in online learning is Massive Open Online Courses (MOOCs) (Siemens, 2013). As Siemens (2013) notes MOOCs are:

- Massive: They allow access to a very large number of students.

- Open: Courses are open to everyone, they are free and it does not require prerequisites.

- Online: Courses are done remotely via the Internet and there is no need to attend at a classroom physically.

- Courses: Courses have a beginning and an end time, and materials may be available after the course has ended.

MOOCs are radically new approach for the access to knowledge both formal and informal methods of learning, and they offer many advantages for learners. For example, these systems are low cost or free; they offer an opportunity for students to enroll for a course offered by high quality universities; they allow participants to continue their professional development or lifelong learning experience and so on (Laxmi \& Gure, 2015).

\section{Method}

In this study, usability of Massive Open Online Course (MOOC) used in mobile platforms was analyzed in terms of user perceptions and opinions. Additionally, the relationship between user perception of usability and user characters (gender, age, level of technology literacy, online course background) was analyzed in details. Research questions that guided this study are as follows:

- What are perceptions of users who take course from MOOCs' mobile platforms about system usability, system usefulness, information quality and interface quality?

- Do these perceptions differ from users' gender, age, level of technology literacy, online course background?

Moreover main objectives of the study are:

- To evaluate the usability of MOOC's used in mobile platforms,

- To identify the key factors affecting the mobile platforms of MOOCs,

- To examine the relationship between the perception of users and individual factors (gender, age, technological literacy and online course background). 
In this study, widely used MOOC systems in educational world which are Coursera, Udacity and Udemy were selected as examples and usability survey was applied to 56 participants about these systems. Participants were selected by paying attention to some of the criteria such as having different gender, age, technological literacy, and online course background. These participants were between the age of 20 and 43 years and they had at least an intermediate level of English. First of all, "User Information Survey" consisting of 10 questions and including personal information were conducted to get demographic information about these users. After that, it was asked to examine these three systems' mobile application for a short time and then complete "Task List" for each system. Next, "Usability of MOOCs in Mobile Platforms" survey was conducted to users. This survey was created by translation of CSUQ (Computer System Usability Questionnaire) into Turkish. CSUQ was developed by IBM. It is widely used in the field of usability and consists of 19 items scored on a 7 point likert scale. Each item was responded on a scale of 1 (Strongly Disagree) to 7 (Strongly Agree). Moreover, items were divided into sections including system usefulness, information quality and interface quality. At the translation of survey, necessary support was received by the subject matter experts. The content validity of the questionnaire items was also examined by the subject matter experts. The reliability of the questionnaire items was processed with SPSS, and Cronbach Alpha and Spearman-Brown reliability coefficients were calculated. The coefficients obtained by these calculations showed the reliability of the questions. The survey data was also processed with SPSS program. In the analyzing of data, Mauchly's sphericity test, repeated measures ANOVA, Bonferroni pair wise comparisons were used.

\section{Result and Discussion}

As a result, there was a significant difference among three systems in terms of system usability, system usefulness, information quality and interface quality. Users' demographic information such as gender, age, technological literacy and online course background was acquired to understand effects of the variables. According to the findings, only age variable has a significant effect in the differences among systems in terms of system usability, system usefulness and information quality.

According to this research, following suggestions can help people design a new MOOC system in a mobile platform:

- The system should be suitable to filter courses; allow users to access courses anywhere and anytime; be easy to use; allow communication between users and instructors; inform users about error and help messages.

- The system should provide support in multiple languages; icons or symbols should represent implied area; titles, phrases, words, concepts should be familiar to users and consistent within themselves; the language should be simple and clear.

- The system should cater to both inexperienced and experienced users; it should allow users to download course materials so as to use them when they do not have an internet access.

- The system should allow users an easy navigation and a flexible mobile environment such as filtering course category, language, content so as to reach the target courses easily. 